\title{
Effect of in situ Ion NitrideTreatment on the Corrosion Behavior of Titanium
}

\author{
Zhenwei Yan", Xianjie Yuan, Zhaojun Tan, Mingqi Tang, Zaiqiang Feng \\ School of Mechanical Engineering, North China University of Water Resources and Electric Power, \\ Zhengzhou 450011, People's Republic of China \\ *E-mail: yanzhenwei@163.com
}

doi: $10.20964 / 2018.01 .23$

Received: 26 August 2017 / Accepted: 23 October 2017 / Online Published: 1 December 2017

\begin{abstract}
Ion nitriding was applied to titanium grade II (TA2) to observe the impact it had on corrosion behavior of Titanium structures. X-ray diffraction, potentiodynamic polarization, electrochemical impedance spectroscopy and Mott-Schottky were used to study the microstructure, electrochemical corrosion properties and semiconducting behaviors of Titanium samples. Cubic TiN and tetragonal $\mathrm{Ti}_{2} \mathrm{~N}$ were formed using ion nitriding treatment. Compared with TA2, ion nitrided TA2 had better resistance to corrosion. The Mott-Schottky curves indicated that the surface layers of TA2 and ion nitride TA2 were not sensitive to the frequency response. TA2 showed n-type and p-type semiconducting behaviors over the potential range measured However, ion nitride TA2 showed only n-type semiconducting behavior.
\end{abstract}

Keywords: Ion nitriding; TA2; Corrosion resistance; Semiconducting behavior

\section{$\underline{\text { FULL TEXT }}$}

(C) 2018 The Authors. Published by ESG (www.electrochemsci.org). This article is an open access article distributed under the terms and conditions of the Creative Commons Attribution license (http://creativecommons.org/licenses/by/4.0/). 